\title{
NAVEGANDO NO MAR DO USO DAS LIVRES CRIAÇÕES: BREVES REFLEXÕES SOBRE O DOMÍNIO PÚBLICO NA PROPRIEDADE INTELECTUAL
}

\begin{abstract}
Angelo da Silva Oliveira ${ }^{1}$
RESUMO: Com o avanço da tecnologia novas formas de proteção têm surgido no campo da Propriedade Intelectual. O domínio público representa um contrapeso ao processo de ampliação de conteúdos protegidos por direitos de exclusiva, um mecanismo democrático que busca o equilíbrio entre a proteção e o acesso. Ele não pode mais ser tratado como algo meramente residual, ao contrário, deve ser reconhecido com um instituto jurídico próprio, com proteção positiva, que assegurem, efetivamente, a livre utilização e circulação do conhecimento científico, técnico e artístico.
\end{abstract}

Palavras-chave: Propriedade Intelectual. Domínio Público. Patentes Pipeline. Royalties.

ABSTRACT: With the advancement of technology new forms of protection have emerged in the field of Intellectual Property. The public domain represents a counterweight to the process of expanding content protected by exclusive rights, a democratic mechanism that seeks the balance between protection and access. It can no longer be treated as merely residual, rather it must be recognized with a proper legal institute, with positive protection, that effectively ensure the free use and circulation of scientific, technical and artistic knowledge.

Keywords: Intellectual Property. Public domain. Pipeline Patents. Royalties.

\section{INTRODUÇÃO}

Ao longo dos anos, o Direito da Propriedade Intelectual tem passado por uma série de transformações realçando o seu caráter expansionista: surgiram novas formas de proteção relativa aos Bancos de Dados e às Topografia de Circuitos Integrados, apareceram novos tipos de suportes gerando um aumento significativo de restrições quanto ao uso do Direito Autorale hoje há discussões até mesmo sobre a ideia de se patentear seres vivos. ${ }^{2}$

Com efeito, tais transformações geraram uma série consequências negativas, dentre as quais o mau aproveitamento ou a subutilização de bens de natureza intelectual em razão

\footnotetext{
1 Advogado. Pós-graduado em direito público. Pós-graduando em direito da propriedade intelectual.

2 NUNES, Claudia Ribeiro Pereira; MELlO, Cleyson de Moraes; RABELO, Leonardo (Coordenadores). Diálogos em Direitos Humanos, Questões Regulatórias em Biotecnologia. Estudos em Homenagem ao Prof. Dr. Pedro Dias Peralta. Iํㅡㄹ
} 
da excessiva proteção de direitos exclusivos. Entraves foram surgindo, comprometendo tanto a promoção da Inovação quanto a própria criação artística.

É justamente nesse cenário intensas medidas protetivas que a figura do Domínio Pública ganha maior protagonismo, à medida que este reforça a livre circulação de conhecimentos técnicos, científicos e artísticos, surgindo como uma alternativa ao excesso de proteção.

Nesse breve estudo se busca uma análise da relação entre Propriedade Intelectual e os efeitos práticos do Domínio Público, ressaltando a importância de se estabelecer um equilíbrio entre a proteção e o seu acesso.

\section{CONTEXTUALIZAÇÃO HISTÓRICA}

Em um interessante trabalho sobre o Domínio Público, o professor Denis Borges Barbosa $^{3}$ traça uma relevante analogia que, pela sua adequação ao tema, vale muito a pena ser resgatada: os conceitos trazidos pelo direito marítimo, cunhados pelo então jurista holandês Hugo Grotius, em sua obra publicada em ı6og sob o título Mare Liberum.

Segmento da história também estudado pela Doutora Heloisa Meireles Gesteira ${ }^{4}$, para ela o jurista holandês defendia a ideia de que o mar não poderia se subsumir ao domínio de qualquer soberania e que, na defesa da liberdade do alto mar, todos os Estados poderiam exercer essa liberdade contra os outros. Para Renata Baptista Zanin 5 , a tese desenvolvida por Grotius é tão importante para o direito internacional público, que ainda sobrevive nos dias atuais nos tratados de direito de alto mar. Curiosamente, em contraponto a tal ideia, os portugueses defendiam a tese do Mare Clausum, muito bem sintetizada nas palavras do seu Rei D. João II $^{6}$, para o qual "os mares que todos devem e podem navegar são aqueles que sempre foram sabidos de todos e comuns a todos, mas os

3 BARBOSA, Denis Borges. O Domínio Público. Disponível em <http://denisbarbosa.addr.com/arquivos/20o/propriedade/dominio_do_publico.pdf >. Acesso em o2 de jul. de 2018.

${ }^{4}$ GESTEIRA, Heloisa Meireles. Da Liberdade Dos Mares: Guerra e Comércio na expansão neerlandesa para o atlântico. Disponível em 〈http://www.revistas.usp.br/revhistoria/article/viewFile/19027/21090〉. Acesso em o2 de jul. de 2018

${ }^{5}$ ZANIN, Renata Baptista O direito do mar e a legislação brasileira: a influência da convenção de montego bay na constituição federal. Disponível em <http://www.esdc.com.br/RBDC/RBDC-I6/RBDC-I6-o83Artigo_Renata_Baptista_Zanin_\%28O_Direito_do_Mar_e_a_Legislacao_Brasileira\%29.pdf >. Acesso em 02 de julho de 2018 .

${ }^{6}$ MERÊA, Paulo. Os Jurisconsultos Portugueses e a Doutrina do “Mare Clausum”. Revista de História, n⿳o 49, Lisboa, 1924, pp. 5-23. 
outros que nunca foram sabidos, nem parecia que se podiam navegar e foram descobertos com grandes trabalhos por mim, esses não”.

Aqui, o ponto de tensão era, justamente, entre aqueles que defendiam a liberdade em auto mar e os que defendiam seu direito monopolístico sobre o mar que fora "descoberto".

Esta analogia é muito interessante, pois podemos ver, claramente, que às vezes o futuro parece, forçosamente, querer repetir o passado.

Aquelas disputas de outrora, sobre a liberdade do alto mar, em muito lembram as atuais disputas do campo da Propriedade Intelectual entre aqueles que defendem um domínio público pujante, em contraponto a aqueles que se agarram com intensidade aos seus direitos de exclusiva.

Talvez, precisamente pelo seu pouco valor econômico para os grandes detentores de capital intelectual - defensores incansáveis dos direitos de exclusiva -, a temática do domínio público nos parece ser um tema negligenciado dentro da Propriedade Intelectual. Afinal, representa o outro lado da moeda, o antagonista do direito de exclusiva, o cemitério dos direitos patrimoniais.

Segundo o professor Denis Borges Barbosa ${ }^{7}$, o tema do Domínio Público só passou a ganhar notoriedade dentro da propriedade intelectual há algumas poucas décadas e que o tema "soou por muito tempo como uma espécie de doença fatal"

Em verdade, a preocupação com o domínio público só passa a existir quando começam a nascer, efetivamente, as primeiras legislações que se dedicam a tratar do tema da Propriedade Intelectual, por volta do século XVIII.

Para Marcos Wachowicz ${ }^{8}$ o marco histórico do conceito moderno do Domínio público é a inauguração do sistema internacional de proteção da propriedade intelectual, pela realização da Convenção da União de Paris para Proteção da Propriedade Industrial (I883) e da Convenção de Berna relativa à proteção das obras literárias e artísticas (I886).

Então, com o surgimento das primeiras legislações limitadoras do uso livre das criações, consequentemente, começa a surgir a reflexão sobre o domínio público. A razão é

\footnotetext{
${ }^{7}$ BARBOSA, Denis Borges. O Domínio Público. Disponível em $\langle$ http://denisbarbosa.addr.com/arquivos/20o/propriedade/dominio_do_publico.pdf $\rangle$. Acesso em o2 de jul. de 2018.

${ }^{8}$ WACHOWICZ, Marcos. Direitos autorais e o domínio público da informação. Disponível em:<https://gedai.com.br/sites/default/files/arquivos/artigo-direitos_autorais_e_a_informacao.pdf >.
} 
muito simples: antes do surgimento dos regulamentos que tratavam dos direitos de exclusiva, tudo estava em domínio público, isto é, não existia regramento para impedir a livre circulação e apropriação de criações expressivas e tecnológicas.

Assim, com os direitos de exclusividade, surge, concomitantemente, o domínio público criativo - como seu antagonista. Nesse sentido, Denis Borges Barbosa ${ }^{9}$ afirma que já no século XIX a noção de domínio público é utilizada para defrontar a ideia da perpetuidade da propriedade intelectual.

O direito da propriedade intelectual é, em verdade, uma grande ficção. Seu principal papel é criar raridade de bens, que por sua natureza intangível, não são raros.

A ideia que molda a propriedade intelectual, atualmente, é que os direitos de exclusiva são necessários porque o custo da criação é extremamente alto, enquanto, de outro lado, o custo da reprodução é extremamente baixo. Assim, uma vez entrado no estado da técnica, as obras podem ser reproduzidas com rapidez sem esgotar o original.

Por essa linha de raciocínio, se não houver a restrição dessa reprodução, o autor não iria conseguir recuperar o investimento feito no seu trabalho criativo e, em consequência, abandonaria seu esforço criativo para dedicar-se a algo mais lucrativo.

Então, para que o criado pudesse buscar, efetivamente, uma compensação em contrapartida à sua criação, foi criado um mercado artificial através das leis de propriedade intelectual, possibilitando a compra e venda dos bens intelectuais.

No entanto esse argumento, de forma alguma, deve ser encarado como uma verdade absoluta, mesmo porque, até em economias planificadas os autores e inventores não deixaram de produzir. A criatividade humana sempre foi é indomável.

Segundo Denis Borges Barbosa ${ }^{\text {Io }}$, alguns fatores fizeram com que fosse dada mais importância ao debate do domínio público. Para o autor, a partir da década de 80 houve um grande aumento na preocupação da proteção dos investimentos feitos em capital intelectual. Como consequência dessa a preocupação exacerbada em proteger os investimentos em bens intangíveis, houve uma proliferação de direitos de exclusiva e

\footnotetext{
${ }^{9}$ BARBOSA, Denis Borges. O Domínio Público. Disponível em 〈http://denisbarbosa.addr.com/arquivos/200/propriedade/dominio_do_publico.pdf >. Acesso em o2 de jul. de 2018.

${ }^{10}$ BARBOSA, Denis Borges. O Domínio Público apud ARAÚJO, Fernando. A Tragédia dos Baldios e dos Anti- Baldios: O Problema Económico do Nível Óptimo de Apropriação. Coimbra: Almedina, 2008. . Disponível em<http://denisbarbosa.addr.com/arquivos/200/propriedade/dominio_do_publico.pdf >. Acesso em 02 de jul. de 2018.
} 
mecanismos de proteção que serviu muito mais para proteger o interesse privado, em detrimento do interesse público.

O efeito dessa maximização de proteção fez surgir o que a doutrina tem denominado como "tragédia dos anti-baldios" ou "tragédia dos anticommons", que segundo CHAMAS, BARATA e AZEVEDO “a metáfora corresponde a uma situação na qual muitos indivíduos lutam pelos direitos de exclusão em um ambiente de recursos escassos". ${ }^{12}$

Os efeitos acabam sendo desastrosos. Há a incidência de tantos direitos de exclusiva sobre determinado bem intelectual, que chega ao ponto de interferir, especialmente, em novas criações derivadas destas, tornando-as praticamente inviáveis.

O domínio público é regra a exclusividade é a exceção.

\section{DEFINIÇÃO DE DOMÍNIO PÚBLICO}

Inicialmente precisamos tecer algumas breves considerações acerca da homonímia do termo domínio público, que pode, se não esclarecido, causar certa confusão quando estudamos o tema. Isto porque, no ramo do Direito Administrativo, a expressão "domínio público" também é utilizada.

Apesar de a expressão ser a mesma, os institutos em si guardam particularidades distintas, entretanto, alguns conceitos trazidos do direito administrativo são úteis para definir a natureza jurídica do domínio público em estudo - afeto ao direito civil.

Em uma leitura clássica do direito administrativo, Hely Lopes Meireles ${ }^{13}$ afirma que a expressão domínio público pode trazer a ideia do poder exercido pelo Estado sobre os bens públicos particulares bem como a natureza condicional desses mesmos bens.

Em um conceito mais moderno, Odete Medauar $_{{ }_{14}}$ explica que a locução domínio público abrange o conjuntos de todos os bens públicos, sejam eles Bens de uso do povo, Bens de uso Especial ou Bens Dominicais.

\footnotetext{
11 HERSCOVICI, Alain. Informação, conhecimento e Direitos de Propriedade Intelectual: os limites dos mecanismos de mercado e das modalidades de negociação privada I A contribuição de Williamson à análise dos Direitos de Propriedade Intelectual. Economia e sociedade, v. 21, n. 3, p. 667-694, 2012. Disponível em:〈http://www.scielo.br/pdf/ecos/v2In3/o8>. Acesso em: I4 jul. 2018.

${ }^{12}$ CHAMAS, Claudia Inês; BARATA, Martha; AZEVEDO, Andreia. Proteção Intelectual de Invenções Biotecnológicas. Disponível em < http://www.anpad.org.br/admin/pdf/enanpad20o4-act-249I.pdf $>$. Acesso em Is de jul. de 2018 .

${ }^{13}$ MEIRELLES, Helly Lopes. Direito Administrativo Brasileiro. 8. Ed. São Paulo: RT, r98ı, p. 478.
} 
Para Denis Borges Barbosa ${ }^{\mathrm{I}}$ tanto o conjunto de bens públicos, quanto o espírito, a cultura, e a inventividade humana são juridicamente res communes omnium, porque ambos não são escassos.

Porém, Sérgio Branco ${ }^{16}$ alerta que o conceito de domínio público do direito administrativo jamais pode confundido com seu homônimo da propriedade intelectual, objeto de nosso estudo.

Antes alcançar sua identidade e conquistar sua autonomia temática e emancipação ${ }^{16}$, a propriedade intelectual foi gestada sob os conceitos dos direitos reais, trazendo em si densa carga da tradição romanística. ${ }^{17}$

Inclusive, o próprio conceito de "propriedade", que é reflexo direto dessa apropriação de conceitos, é de aplicação extremadamente discutível em relação à própria ideia de propriedade intelectual. Alguns autores simplesmente partem para um esforço de objetivo interpretação ignorando problemas conceituais, enquanto outros apontam a que tal conceito é extremamente contra intuitivo e problemático.

Novamente, para construirmos o conceito de domínio público, precisamos recorrer aos direitos reais. Denis Borges Barbosa afirma que a noção do que seja o domínio público pode ser extraída do conceito de baldios ${ }^{18}$.

${ }^{14}$ MEDAUAR, Odete.Direito Administrativo moderno. 2r. Ed. Belo Horizonte: Fórum, 20r8, p. 235.

${ }^{15}$ BARBOSA, Denis Borges. Domínio público e patrimônio cultural. Disponível em: $\langle$ http://www.gestioncultural.org/boletin/2006/bgci5-DBorges.pdf〉. Acesso em og de jul. 2018.

${ }^{16}$ BRANCO, Sérgio. O domínio público no direito autoral brasileiro: uma obra em domínio público. Lumen Juris, 2011, p 55 .

${ }^{16}$ ARONNE, Ricardo. Propriedade intelectual e direitos reais um primeiro retomar da obviedade. Disponível em<https://online.unisc.br/seer/index.php/direito/article/view/186/147> . Acesso em o9 Jul.2018, p. 213.

${ }^{17}$ BARBOSA, Denis Borges. O Conceito de Propriedade Intelectual. Disponível em 〈http://www.egov.ufsc.br/portal/sites/default/files/anexos/27573-27583-I-PB.pdf〉. Acesso em o9 Jul. 2018.

18 Os baldios são as "terras incultas, matos maninhos, ou matas e bravios, que nunca foram lavrados e aproveitados, ou não ha memória de homens que o fossem, os quais não foram contados, nem reservados" (Ordenações Filipinas, Livro IV, tido 43, § 9) ao uso especial ou à segregação de que cogita o art. 66, II. As Ordenações Filipinas diziam: "nem reservados pelos Reis, que ante Nós foram, e passaram geralmente pelos Forais com as outras terras aos povoados delas". Tais baldios não se podiam dar em sesmaria, nem se permitia rateá-los, se fosse contra "o proveito geral dos moradores nos pastos dos gados, criações e logramento da lenha e madeira para suas casas e lavouras”. Percebe-se a influência da concepção romana da universitas personarum (cf. Alvará de 27 de novembro de 1804 , arts. 47r e 473), mas ao fundo está a instituição da propriedade comum germânica (Código Visigótico, Livro VIII, Título 5, L. 2 e L. 5, e Título 3, L. I2). O Código Civil, art. 646, prevê a legislação municipal sobre os baldios, aliás, sobre os terrenos, quaisquer, de que trata o art. 66, I (bens de uso comum do povo, tais como os mares, rios, estradas, ruas e praças), ressalvado o que for da competência da União ou dos Estados-membros. MIRANDA, Francisco Cavalcanti Pontes de. Tratado de Direito Privado. § I.4I3. Rio de Janeiro: Borsoi. 
Ao que tudo indica, o termo surge em Portugal ${ }^{19}$, no século XIV, e aparece pela primeira vez na legislação, nas Ordenações Manuelinas. Daí para frente o termo foi sendo lentamente difundido, até que, a partir de do ano de 1744 passou a figurar frequentemente na legislação portuguesa.

Os baldios nada mais são do que terras não cultivadas, não individualmente apropriadas, destinadas a servir ao usufruto comum dos moradores de um determinado local ou um grupo de moradores de locais diversos (esses logradouros comuns podem consistir em áreas para aproveitamento de pastagem de gado, de águas, ervas, lenhas e madeira, e espaços de transumância).

Segundo Lemos $^{20}$, na língua inglesa também existe um termo para se referir ao pedaço de terra de uso comum, é o chamado "commons". Ainda, segundo mesmo autor, no Brasil ainda não há um tradução perfeita para o termo, porém, no nordeste é utilizada a expressão "solta" para se referir a lugares onde o gado é criado livremente por qualquer um. Esse engenho linguístico regional é o mais próximo que temos do conceito de baldio no nosso País.

No âmbito da propriedade intelectual, o domínio público pode ser definido como o estado jurídico consistente no livre acesso e utilização de criações intelectuais, sendo estas expressões ou inovações industriais, sobre as quais não incide mais qualquer direito de exclusiva, sendo desnecessário, portanto, qualquer autorização ou pagamento pelo seu uso.

Tais bens intelectuais não podem ser mais apropriados, pois pertencem à coletividade, podendo vir a ser utilizado por qualquer um do povo.

A partir do conceito de baldios, Denis Borges Barbosa traça um paralelo com o domínio público, explorando todas as suas características comuns.

Assim, para aquele autor, tanto os baldios quanto o domínio público são espaços irredutíveis ao controle privado de um único agente, não estão sujeitos à apropriação exclusiva e todos têm legitimidade para defendê-lo.

19 RODRIGUES, Eugénia. 2014. "Prazos da coroa", in J. V. Serrão, M. Motta e S. M. Miranda (dir), eDicionário da Terra e do Território no Império Português. Lisboa: CEHC-IUL. (ISSN: 2183-I408). Disponível em<https://edittip.net/2014/o3/o4/baldios/>. Acesso em I8 de jul. de 2014.

20 LEMOS, Ronaldo. Creative Commons, mídia e as transformações recentes do direito da propriedade intelectual. Revista Direito GV, v. I, n. I,2005, p.I8r.Disponível em<http://bibliotecadigital.fgv.br/dspace/bitstream/handle/10438/2797/Creative_Commons_Midia_e_Transfo rmaco es_recentes_do_Direito_da_PI.pdf?sequence $=\mathrm{I} \&$ is Allowed $=y>$. Acesso em: í de jul. de 2018. 


\section{A FUNÇÃO DO DOMÍNIO PÚBLICO}

A determinação desse espaço de "informação e conhecimento livre e liberalizado", embora entregue à lei, está exposta ao debate jurídico-político, motivo pelo qual gera discussões ideológicas árduas.

Certo é que, a existência de um vigoroso domínio público é uma autoridade crucial para o sistema de direitos de propriedade intelectual. Sem o Domínio Público, pode ser impossível tolerar os direitos de exclusividade.

Nesse sentido, Ascenção ${ }^{2 \mathrm{I}}$ é categórico ao afirmar que não é o domínio público que terá que encontrar uma justificativa em si, mas ao contrário, é o exclusivo, como exceção a essa comunicação livre em comunidade, que tem que demonstrar a sua validade.

O domínio público é um fator essencial para o desenvolvimento da sociedade. Sua existência é a garantia de uma gama de bens intelectuais disponíveis a quaisquer interessados, já desembaraçados da exploração econômica.

É a partir dessas criações que terceiros interessados poderão desenvolver novas obras a partir de sua reprodução, exploração, combinação ou modificação. Para o mesmo autor, o domínio público é uma forma de retorno à sociedade de algo que ela mesma legitimou ao criador da obra, como se fosse um resgate do que foi propiciado.

Então, em sua essência o Domínio Público é um grande oceano de matéria prima livre, disponível para ser utilizada em novas criações (que um dia também integrarão o domínio público), possibilitando um ciclo (virtuoso) de inovações continuas.

Um domínio público fortalecido é um instrumento capaz de promover a eficácia de alguns direitos fundamentais, como o direito à educação, à cultura e à informação.

A própria Organização Mundial da Propriedade Intelectual (OMPI) ${ }^{22}$, reconhecendo a importância do tema, vem buscada cada vez mais o aprimorando do tratamento dado ao Domínio Público, inclusive, editando as recomendações i6 e 20, assinalando para os países membro a necessidade e preservação e promoção de um domínio público robusto.

\footnotetext{
${ }^{21}$ ASCENSÃO, José Oliveira. Direito Autoral. 2 Ed. Rio de Janeiro: Renovar, 1997, p. 353.

${ }^{22}$ Project On Intellectual Property And The Public Domain (Recommendations i6 And 20). Disponível em 〈http://www.wipo.int/edocs/mdocs/mdocs/en/cdip_4/cdip_4_3_rev.pdf〉. Acesso em Ir jul.2or8.
} 
Além disso, outro efeito curioso do domínio público é a criação de novos modelos de negócios a partir de obras ali inseridas.

Em sua maioria, as obras são exploradas comercialmente por um período relativamente curto, a exceção são aquelas de grande sucesso, que mesmo entrando em domínio público, ainda têm grande possibilidade de serem rentáveis.

Contudo, Lessig alerta:

O verdadeiro dano [produzido pelos longos prazos protetivos, bem como pela inexistência de um domínio público efetivo] é gerado aos trabalhos que não são famosos, nem explorados comercialmente, e que, como resultado, não estão mais disponíveis. ${ }^{23}$ "

Por não estarem mais protegidas por direitos patrimoniais, podem ser reeditadas e relançadas no mercado com um custo de reprodução e reinserção bem menores.

Com isso, tem-se o efeito de ter sempre a disposição e circulando, exemplares dessas determinadas obras, causando um efeito benigno de que a obra não seja esquecida com o passar dos anos.

O domínio público é a base da auto compreensão expressa pelo nosso conhecimento e cultura acumulados compartilhados por anos. Nas palavras de James Boyle.24:

Nossos mercados, nossa democracia, nossa ciência, nossas tradições de livre expressão e toda nossa arte dependem mais fortemente de um material disponível livremente em Domínio Público do que de obras protegidas por direitos patrimoniais. O Domínio Público não é um resíduo deixado para trás quando todas as coisas boas já foram tomadas pelo direito de propriedade. O Domínio Público é compõe a estrutura que suporta a construção da nossa cultura. Ele é, na verdade, a maior parte da nossa cultura.

\section{A BATALHA PELO DOMÍNIO PÚBLICO}

Sem sombras de dúvidas, o destino final de todo bem intelectual, mais cedo ou mais tarde, é o Domínio Público. É o ciclo natural: criador materializa sua ideia, ganha proteção de uma exclusiva, e ao final, sua criação fica disponível ao resto da humanidade.

Porém, por mais natural que pareça, o domínio público ainda encontra muita resistência. De tempos em tempos, surgem legislações que buscam aumentar o prazo de

\footnotetext{
23 LESSIG, Lawrence. Cultura livre: como a grande mídia usa a tecnologia e a lei para bloquear a cultura e controlar a criatividade. Trama, 2005, p. 222.

24 BOYLE, James. The public domain: Enclosing the commons of the mind. 2008. Disponível em: <https://scholarship.law.duke.edu/cgi/viewcontent.cgi?referer=https://scholar.google.com.br/\&httpsredir=I\& arti cle $=5385 \&$ context $=$ faculty_scholarship $>$. Acesso em o9 jul. 2018.
} 
proteção por exclusiva, especialmente em direito autoral. Tais ações, a contrario sensu, representam um preocupante ataque direto ao Domínio Público.

Assim, por sua importância, selecionamos alguns casos marcantes que representaram verdadeira afronta ao Domínio Público.

\subsection{O caso Sonny Bono Act}

Para nós, um dos casos mais emblemáticos ocorreu em 1998, nos Estados Unidos da América. Seguindo a tendência dos estados membros da União Europeia - que em 1993 ampliaram a proteção autoral por mais 70 anos após sua morte -, naquele ano, pressionados pelos grandes detentores de direitos autorais, o Congresso Americano publicou o Copyright Term Extension Act ${ }^{25}$ (CTEA), que ficou mais conhecido como Sonny Bono ${ }^{26}$ Act.

Por meio dessa legislação, o prazo de proteção do autor (pessoa física) passou de 50 para 70 anos após a morte do autor, bem como, 75 anos após a publicação para obras criadas por empresas (pessoas jurídicas).

Sarcasticamente, essa lei também ficou conhecida por um apelido curioso: Mickey Mouse Protection Act. Porém, a explicação é simples: um dos maiores lobistas para a aprovação daquela lei foi a gigante Walt Disney Company $^{27}$, isto porque, seu personagem mais famoso, o Mickey Mouse, estava na iminência a entrar em domínio público - mais precisamente, em 2003, caso o Act não fosse aprovado.

Porém, o mais irônico nesse caso é que Walter Elias Disney ${ }^{28}$, o fundador da companhia e criador do icônico personagem, por diversas vezes utilizou de obras em domínio publico para começar seu império, especialmente, as dos irmãos Irmãos Grimm. ${ }^{29}$

\footnotetext{
${ }^{25}$ Copyright Term Extension Act . Disponível em <https://www.copyright.gov/legislation/s505.pdf >. Acesso em o8 jun.20r8.

${ }^{26}$ Salvatore Phillip "Sonny" Bono (Detroit, i6 de fevereiro de 1935 - South Lake Tahoe, 5 de janeiro de 1998) foi um produtor discográfico, cantor, ator e político norte-americano.

${ }^{27}$ VIEIRA, Alexandre Pires. Direito Autoral na Sociedade Digital. I ${ }^{\mathrm{a}}$ ed. São Paulo, SP: Montecristo Editora, 2011, p. $23 / 24$.

${ }^{28}$ Walter Elias Disney, conhecido por Walt Disney (Chicago, 5 de dezembro de I9or - Los Angeles, I5 de dezembro de 1966), foi um produtor cinematográfico, cineasta, diretor, roteirista, dublador, animador, empreendedor, filantropo e co-fundador da The Walt Disney Company.

${ }^{29}$ Jacob Ludwig Karl Grimm (Hanau, 4 de janeiro de 1785 - Berlim, 20 de setembro de 1863 ) e Wilhelm Karl Grimm (Hanau, 24 de fevereiro de 1786 - Berlim, 16 de dezembro de 1859), foram dois irmãos, ambos acadêmicos, linguistas, poetas e escritores.
} 
A oposição à Lei de Extensão de Direitos Autorais de Sonny Bono foi relativamente branda, principalmente porque trazia em si enormes benefícios econômicos para os proprietários de direitos autorais dos EUA.

No entanto, quase 60 professores de direito assinaram uma declaração contrária à extensão do prazo de direitos autorais ${ }^{30}$. Eles argumentaram que a proteção dos direitos autorais já era longa o suficiente para fornecer incentivos suficientes para a criação de novos trabalhos e que a extensão do termo seria contrária ao interesse do público em um "domínio público vibrante", necessário para incentivar novas criações baseadas na livre acessibilidade. de obras fora de direitos autorais.

A lei chegou a ser questionada judicialmente no caso Eldred v. Ashcroft ${ }^{3 \mathrm{H}}$, entretanto, a decisão da Suprema Corte Americana, por sete votos a dois, foi pela sustentação da constitucionalidade da Lei de Extensão de Direitos Autorais de Sonny Bono.

A decisão, em verdade, beneficiou as grandes empresas de mídia e as gravadoras que corriam o risco de perderem royalties - e representou uma enorme derrota para acadêmicos, artistas e editores de conteúdo de sites, que questionavam o viés limitador e excludente da referida legislação.

\subsection{As patentes pipeline}

Mudando a direção dos ventos, nos voltamos agora a um tema especialmente polêmico dentro da Propriedade Industrial, que, também, de certa forma, foi mais um ataque ao Domínio Público. Trata-se do tema das patentes Pipeline (também conhecidas como patentes de importação" ou "patentes de revalidação").

O sistema pipeline foi um instituto temporário de concessão de patentes introduzido em nosso ordenamento jurídico através da Lei $\mathrm{n}^{\mathrm{o}}$ 9.279/96, que criou a possibilidade de pelo período de um ano - entre maio de 1996 e maio de 1997 -, fossem depositadas patentes em áreas tecnológicas que não eram abrangidas pela Lei de Propriedade Industrial anterior

\footnotetext{
${ }^{30}$ Statement of Copyright and Intellectual Property Law Professors in Opposition to H.R. 604, H.R. 2589, and S.505 (1998). Disponível em 〈http://homepages.law.asu.edu/ dkarjala/OpposingCopyrightExtension/legmats/1998Statement.html〉. Acesso em o9 de Jul. de 2018.

${ }^{31}$ Disponível em: < https://supreme.justia.com/cases/federal/us/537/r86/case.pdf>. Acesso em 21 jul. 2018.
} 
(Lei 5.772/1971), mas que já se encontravam patenteados no exterior. Ou seja, é um mecanismo de transição que possibilitava a revalidação de patentes estrangeiras no Brasil.

Entretanto, de outro lado, o grande problema trazido por esse mecanismo é que, abruptamente, passou-se a ser permitido o patenteamento de produtos que já se encontravam em domínio público, ou seja, produtos que não eram protegidos por exclusiva e, portanto, já pertenciam à coletividade (v.g. medicamentos, alimentos e processos químicos farmacêuticos). Por conta dessa significante alteração, o instituto das patentes pipeline foi alvo de diversos questionamentos judicias, sendo, inclusive, reconhecida sobre a possibilidade de o Poder Legislativo editar normas que atribuíssem patentes ao que já estava em domínio público, conforme decisão exarada pela Primeira Seção Especializada do TRF da 2ª Região. Para a então Relatora Desembargadora Liliane Roriz: "Não tem o Poder Legislativo competência para editar leis que atribuam patentes para o que já se encontra no estado da técnica e no domínio público como rescommunis omnium." ${ }^{22}$

Ademais, estudiosos da propriedade intelectual como Denis Borges Barbosa ${ }^{33}$ defendem a inconstitucionalidade do instituto das patentes pipeline, com o argumento de que a concessão de tais patentes violaria o próprio requisito da novidade para a concessão da proteção por exclusiva exigido pelo art. 8ㅇ da própria Lei 9.279/96 bem como afrontaria o princípio da inderrogabilidade do domínio público.

A jurisprudência do $\mathrm{TRF}_{2}$ trouxe o argumento de que as patentes pipeline trazem emsi verdadeira violação ao direito adquirido, nesse sentido:

Ao prever em seu artigo 230 a possibilidade da revalidação de patente estrangeira no Brasil (pipeline), a Lei n. ${ }^{\circ}$ 9.279-96 atentou contra o princípio insculpido no inciso XXXVI do artigo 5. ${ }^{\circ}$ da Constituição, já que uma série de inventos que, sob a égide da legislação revogada, encontravam-se em domínio público passaram a ser objeto de proteção intelectual, fato que representa violação ao direito adquirido dos nacionais anteriormente consolidados. ${ }^{34}$

\footnotetext{
32 BRASIL. Tribunal Regional Federal da 2- Região. Embargos Infringentes n. o0o7453-54.2000.4.02.00oo (TRF2 2000.02.01.007453-0). Primeira Seção Especializada. Relatora: Des. Fed. Liliane Roriz. Rio de Janeiro. J. em: 30/o8/2007. Disponível em: $<$ http://wwwio.trf2.jus.br/portal/?movimento= oJ:ementas.trf2.jus.br/siapro/feeder/idx\%_index\&lr=lang_pt\&ie $=U T F \& \& o u t p u t=x m l \_n o \_d t d \& a c c e s s=p \& o e=$ UTF-8> . Acesso em: 22 jul. 2018.

${ }^{33}$ BARBOSA, Denis Borges. Inconstitucionalidade das Patentes Pipeline. Disponível em: $\langle$ http://denisbarbosa.addr.com/pipeline.pdf 〉. Acesso em 22 jul.2or8.

34 BRASIL. Tribunal Regional Federal da 2 $2^{\underline{a}}$ Região. Apelação Cível no o500712-85.2005.4.02.5101 (TRF2 2005.51.01.500712-8). 2 ${ }^{\mathrm{a}}$ Turma Especializada. Relator: Des. Fed. André Fontes. Rio de Janeiro. J. em: 28/03/2007. Disponível em:<http://wwwio.trf2.jus.br/portal/? nph3zvd9HzIJ:ementas.trf2.jus.br/siapro/feeder/i
} 
Com base nesses argumentos, em 2009, a Procuradoria Geral da República ajuizou Ação Direta de Inconstitucionalidade no. 4.234, questionando a legalidade dos arts. 230 e 231 da Lei no 9.279/1996 (dispositivos que preveem as patentes “pipeline”).

Sob a relatoria da ministra Cármen Lúcia, atualmente a ação conta com I4 entidades que participam como amicus curiae, o que demonstra a importância do caso, não só para as indústrias farmacêuticas, como também, para o Sistema Único de Saúde (SUS).

Lamentavelmente, dado a importância do tema, mesmo após nove anos depois de chegar ao Supremo Tribunal Federal (STF), a ADI permanece, ainda, sem julgamento de mérito - que está previsto para ocorrer em meados de setembro de 2018.

Esse Julgamento é de extrema relevância, pois a concessão de patentes para produtos que se encontravam em domínio público, sem dúvidas, criou entraves no acesso a tais bens (como é o caso dos medicamentos), seja por limitação a sua produção ou por aspectos puramente financeiros.

Um bom exemplo que comprova essa afirmativa foi a disputa judicial ocorrida entre a Libbs Farmacêutica contra a Bayer Schering Age o INPI. A Libbs ajuizou a demanda buscando anular a patente da substância di-hidroespirorenona (componente de alguns anticoncepcionais), concedida a Bayer, na modalidade "pipeline".

Ao julgar o caso (REsp 1.201.454 / RJ), o STJ entendeu que não há a necessidade da novidade para as patentes de revalidação e concedeu a patente da substância para a Bayer, pois:

O sistema de patentes pipeline, também chamado de "patente de importação" ou "patente de revalidação", compreende patentes extraordinárias e transitórias, e possibilita a outorga de proteção a inventos cujo patenteamento não era autorizado pela legislação brasileira anterior ao atual diploma normativo (qual seja, a Lei $\mathrm{n}^{\mathrm{o}} 5.772 / \mathrm{r} 97 \mathrm{I}$ ), tais como produtos químicos, produtos e processos químico- farmacêuticos, medicamentos de qualquer espécie, produtos alimentícios, dentre outros. ${ }^{35}$

Assim, uma substância que poderia ser utilizada, livremente, por diversos fabricantes de medicamento, passou a ser só utilizada somente pelo titular da patente - ou por terceiros mediante licença e pagamento de royalties.

dx\%3Fprocesso\%3D200551015007128\%26CodDoc\%3Di63759+\&site=v2_jurisprudencia\&client=v2_index \&p roxystylesheet=v2_index\&lr=lang_pt\&ie=>. Acesso em. 22 jul. 2018.

${ }^{35}$ BRASIL. Superior Tribunal de Justiça. Recurso Especial no I.201.454 / RJ. Terceira Turma. Relator: Ministro Ricardo Villas Bôas Cueva. Brasília.J. em: 14/10/2014. Disponível em: < https://ww2.stj.jus.br/processo/revista/documento/mediado/?componente $=$ ITA \&sequencial= $1355830 \&$ num_reg i stro $=201001184336 \&$ data $=20141031 \&$ formato $=P D F>$. Acesso em 22 jul.2018. 
A consequência financeira privatizar um bem em domínio público, sem analisar o mérito do pedido de patente, é clara: o produto forçosamente terá um sobre preço e será mais limitado para o mercado consumidor.

\subsection{O Domínio Público Remunerado}

De um modo geral, os bens intelectuais contidos no domínio público podem ser explorados, de forma livre, por qualquer um do povo, com ou sem intenção de lucro, independentemente de qualquer pagamento de direito de exclusiva ou de tributos. É, em sua acepção clássica, uma zona de livre exercício.

Entretanto, como assevera Antonio Chaves ${ }^{36}$, sob o pretexto de que o domínio público tradicional não teria correspondido adequadamente às suas finalidades, começaram a surgir em alguns países a ideia de um domínio público remunerado, que se distingue do tradicional pelo fato de que, ainda que o bem intelectual continue à disposição de qualquer interessado, seu acesso fica restringido ao pagamento de uma retribuição, instituída por lei, a algum beneficiário - que pode ser uma entidade estatal ou não.

A nosso ver, o grande problema gerado por esse domínio público é o fato deste constituir, em verdade, uma imposição parafiscal cujo efeito é onerar a exploração das obras do espírito que já estavam em domínio comum. Cria-se um óbice totalmente desarrazoado à fruição dos bens, e para piorar, causa um desequilíbrio em nível internacional, já que, obviamente, desfavorece os usuários dos países que consagram esta instituição em relação aos estados que a ignoram.

Os defensores do domínio público remunerado costumam tentar embasar seus argumentos em nobres justificativas, como por exemplo, a defesa da Cultura ao sugerir que os valores pagos pelo acesso as obras sejam revertidos à instituições culturais.

Entretanto, devemos estar sempre atentos a esse tipo de discurso proselitista, isto porque, em seu substrato, muitas vezes, esconde as vozes da indústria do copyright, que buscam, na realidade, embaraçar e criar dificuldades econômicas para aqueles que, de alguma maneira, exploram os bens disponíveis no domínio público, minando, portanto,

36 CHAVES, Antônio. Domínio Público No Brasil-Aspectos Patrimoniais-Domínio Público RemuneradoLicença Legal E Licença Compulsória. Revista de Direito PGE-GO, v. I8, 2013. Disponível em: 2 http://www.pge.go.gov.br/revista/index.php /253/23I〉. Acesso em: 22 jul.2018. 
qualquer tipo de concorrência. Como bem lembra Jose De Oliveira Ascensão, o "domínio público, como toda a zona de liberdade, suscita grandes cobiças." 37

Certo é que, como defendemos ao longo desse trabalho, a existência de um domínio público robusto, livre e gratuito é uma forma de se estimular a criação intelectual. Portanto, por menor que seja a limitação do uso de obras em domínio público, esse ato por si só será minimamente abusivo ${ }^{38}$

\section{CONCLUSÃO}

Como as correntes marítimas, os bens intelectuais têm seu ciclo próprio. Inicialmente é destinado ao uso comercial, onde cessado o termo legal da proteção por exclusiva, passa a cumprir uma nova função como vetor informacional, apesar de não ser mais, por si só, economicamente rentável.

É nesse segundo momento do ciclo dos bens intelectuais que eles passam a pertencer ao acervo de domínio público, garantindo que a sua existência não comercial seja efetiva e seu aproveitamento por qualquer interessado seja pleno.

O domínio público representa um contrapeso ao processo de ampliação de conteúdos protegidos por direitos de exclusiva, um mecanismo democrático que busca o equilíbrio entre a proteção e o acesso.

Desse modo, torna-se imperioso que os Estados tomem medidas capazes de ajustar suas normas de propriedade intelectual para que tragam uma proteção positiva do domínio público, especialmente, pelos constantes e sistemáticos ataques à sua existência, bem como, pelos novos desafios trazidos pela sociedade da informação. Do mesmo modo que Grotius defendia a liberdade em alto mar, para nós, cabem a todos os Estados a defesa desse ambiente de liberdade propiciado pelo domínio público.

Assim, acima de tudo, o domínio público não pode mais ser tratado como algo meramente residual, ao contrário, deve ser reconhecido com um instituto jurídico próprio, com proteção positiva, que assegurem, efetivamente, a livre utilização e circulação do conhecimento científico, técnico e artístico.

37 ASCENSÃO, José de Oliveira. A questão do domínio público. In: WACHOWICZ, Marcos e SANTOS, Manoel J. Pereira dos. Estudos de Direito de Autor e Interesse Público: Anais do II Congresso de Direito de Autor e InteressePúblico. Florianópolis: Fundação Boiteux, 2008. Disponível em: 〈http://www.direitoautoral.ufsc.br/arquivos/anais_na_integra.pdf> Acesso em: 22 de jul. de 2018.

${ }^{38}$ BRANCO, Sérgio. O domínio público no direito autoral brasileiro: uma obra em domínio público. Lumen Juris, 201I, p o3. 


\section{REFERÊNCIAS}

ARONNE, Ricardo. Propriedade intelectual e direitos reais um primeiro retomar da obviedade. Disponível em <https://online.unisc.br/seer//186/147> . Acesso em o9 Jul.2018.

ASCENSÃO, José Oliveira. Direito Autoral. 2ª Ed. Rio de Janeiro: Renovar, 1997.

ASCENSÃO, José de Oliveira. A questão do domínio público. In: WACHOWICZ, Marcos e SANTOS, Manoel J. Pereira dos. Estudos de Direito de Autor e Interesse Público: Anais do II Congresso de Direito de Autor e Interesse Público. Florianópolis: Fundação Boiteux, 2008. Disponível em: 〈http://www.direitoautoral.ufsc.br/arquivos.pdf 〉 Acesso em: 22 de jul. de 2018.

BARBOSA, Denis Borges. O Domínio Público. Disponível em: $\langle$ http://denisbarbosa.addr.com/arquivos/200/propriedade/dominio_do_publico.pdf $\rangle$.Acesso em o2 de jul. de 2018.

BARBOSA, Denis Borges. O Domínio Público apud ARAÚJO, Fernando. A Tragédia dos Baldios e dos Anti-Baldios: O Problema Económico do Nível Óptimo de Apropriação. Coimbra:Almedina,2008. Disponível em: <http://denisbarbosa.addr.com/arquivos/20o /dominio_do_publico.pdf $>$.Acesso em 02 de jul. de 2018.

BARBOSA, Denis Borges. Domínio público e patrimônio cultural. Disponível em: $\langle$ http://www.gestioncultural.org/boletin/2006/bgci5-DBorges.pdf $\rangle$. Acesso em o9 de jul. 2018.

BARBOSA, Denis Borges. O Conceito de Propriedade Intelectual. Disponível em $\langle$ http://www.egov.ufsc.br/portal/sites/default/files/anexos/27573-27583-I-PB.pdf $>$. Acesso em 09 Jul. 2018.

BARBOSA, Denis Borges. Inconstitucionalidade das Patentes Pipeline. Disponível em: $\langle$ http://denisbarbosa.addr.com/pipeline.pdf〉. Acesso em 22 jul.2018.

BOYLE, James. The public domain: Enclosing the commons of the mind. 20o8. Disponível em: <https://scholarship.law.duke.edu/cgi/viewcontent.cgi?referer=https://scholar.google.com.br/ $\&$ httpsredir $=\mathrm{I} \&$ article $=5385 \&$ context $=$ faculty_scholarship $>$. Acesso em o9 jul. 2018.

BRASIL. Tribunal Regional Federal da $2^{\underline{a}}$ Região. Embargos Infringentes n. o00745354.2000.4.02.0000 (TRF2 2000.02.01.007453-0). Primeira Seção Especializada. Relatora: Des. Fed. Liliane Roriz. Rio de Janeiro. J. em: 30/08/2007. Disponível em: $<$ http://wwwio.trf2.jus.br/portal/?movimento=cache\&q=cache:j2iAdKmDurf2.jus.br/siap ro/feeder/idx\%3F processo\%3D200002010074530\%26CodDoc\%3Di76985+\&site=v2_jurispru dencia\&client $=$ v2_index \& proxystylesheet $=$ v2_index\&lr $=$ lang_pt\&ie $=U T F 8 \&$ output $=x \mathrm{ml}$ no_dtd\&access=p\&oe=UTF-8> . Acesso em: 22 jul. 2018.

BRASIL. Tribunal Regional Federal da 2 a $^{-}$Região. Apelação Cível no $0500712-$ 85.2005.4.02.5101 (TRF2 2005.51.01.500712-8). 2 ${ }^{\mathrm{a}}$ Turma Especializada. Relator: Des. Fed André Fontes. Rio de Janeiro. J. em: 28/03/2007. Disponível em: 
http://wwwio.trf2.jus.br/portal/?movimento=cache\&q=cache:nph3zvd9HzIJ:ementas.trf2. ju s.br/siapro/feeder/idx\%3F processo\%32D200551015007128\%26CodDoc\%3Di63759+\&site =v 2_jurisprudencia\&client=v2_index\&proxystylesheet $=v 2 \_$index \&lr $=$lang_pt\&ie8\&output $=\mathrm{x}$ ml_no_dtd\&access=p\&oe=UTF-8>. Acesso em. 22 jul. 2018.

BRASIL. Superior Tribunal de Justiça. Recurso Especial no 1.20I.454 / RJ. Terceira Turma. Relator: Ministro Ricardo Villas Bôas Cueva. Brasília. J. em: I4/ı/2014. Disponível em: <https://ww2.stj.jus.br/processo/revista/documento/mediado/?componente=ITA\&seque ncial $=1355830 \&$ num_registro $=201001184336 \&$ data $=2014103 \mathrm{I} \&$ formato $=\mathrm{PDF}>$. Acesso em 22 jul.2018.

BRANCO, Sérgio. O domínio público no direito autoral brasileiro: uma obra em domínio público. Lumen Juris, 2oII.

CHAMAS, Claudia Inês; BARATA, Martha; AZEVEDO, Andreia. Proteção Intelectual de Invenções Biotecnológicas. Disponível em: 〈http://www.anpad.org.br/admin/pdfact249I.pdf > . Acesso em is de jul. de 2018.

CHAVES, Antônio. Domínio Público No Brasil-Aspectos Patrimoniais-Domínio Público Remunerado-Licença Legal E Licença Compulsória. Revista de Direito PGE-GO, v. I8, 2013.Disponível em: 〈http://www.pge.go.gov.br/revista / revistapge/article /253/23I〉. Acesso em: 22 jul.2018.

GESTEIRA, Heloisa Meireles. Da Liberdade Dos Mares: Guerra e Comércio na expansão neerlandesa para o atlântico. Disponível em< http://www.revistas.usp.br/revhistoria $>$. Acesso em 02 de jul. de 2018.

HERSCOVICI, Alain. Informação, conhecimento e Direitos de Propriedade Intelectual: os limites dos mecanismos de mercado e das modalidades de negociação privada i A contribuição de Williamson à análise dos Direitos de Propriedade Intelectual. Economia e sociedade, v. 2I, n. 3, p. 667-694, 2012. Disponível em: 〈http://www.scielo.br/pdf/ecos/v2rn3/o8>. Acesso em: I4 jul. 2018.

LEMOS, Ronaldo. Creative Commons, mídia e as transformações recentes do direito da propriedade intelectual. Revista Direito GV, v. I, n. I,2005, p.I8I. Disponível em: <http://bibliotecadigital.fgv.br/dspace/bitstream/handle/ı0438/2797/Creative_Commons _Mid ia_e_Transformacoes_recentes_do_Direito_da_PI.pdf?sequence $=$ I\&isAllowed $=y>$. Acesso em: i9 de jul. de 2018.

LESSIG, Lawrence. Cultura livre: como a grande mídia usa a tecnologia e a lei para bloquear a cultura e controlar a criatividade. Trama, 2005.

MEDAUAR, Odete. Direito Administrativo moderno. 2r. Ed. Belo Horizonte: Fórum, 2018. MEIRELLES, Helly Lopes. Direito Administrativo Brasileiro. 8. Ed. São Paulo: RT, I98I

MEREAA, Paulo. Os Jurisconsultos Portugueses e a Doutrina do "Mare Clausum". Revista de História, no 49, Lisboa, 1924. 
NUNES, Claudia Ribeiro Pereira; MELLO, Cleyson de Moraes; RABELO, Leonardo (Coordenadores). Diálogos em Direitos Humanos, Questões Regulatórias em Biotecnologia. Estudos em Homenagem ao Prof. Dr. Pedro Dias Peralta. ia ed. Rio de Janeiro: Processo, 2018.

RODRIGUES, Eugénia. 2014. "Prazos da coroa", in J. V. Serrão, M. Motta e S. M. Miranda (dir), e-Dicionário da Terra e do Território no Império Português. Lisboa: CEHC-IUL. (ISSN: 2183-I408). Disponível em 〈https://edittip.net/2014/o3/o4/baldios/> . Acesso em i8 de jul. de 2014 .

VIEIRA, Alexandre Pires. Direito Autoral na Sociedade Digital. I $^{\text {a }}$ ed. São Paulo, SP: Montecristo Editora, 20Ir.

WACHOWICZ, Marcos. Direitos autorais e o domínio público da informação. Disponível em:<https://gedai.com.br/sites/default/files/arquivos/artigodireitos_autorais_e_a_informa cao.pdf $>$. Acesso em 02 de jul. de 2018.

ZANIN, Renata Baptista O direito do mar e a legislação brasileira: a influência da convenção de montego bay na constituição federal. Disponível em 〈http://www.esdc.com.br/Artigo_Renata_Baptista_Zanin_\%28O_Direito_do_Mar_e_a_Leg islacao_Brasileira\%29.pdf >. Acesso em 02 de jul. de 2018. 